\title{
Chapter 1 \\ Making Sense of Community and Identity in Twenty-First Century Technoscience
}

\author{
Karen Kastenhofer and Susan Molyneux-Hodgson
}

\subsection{New Wine in Old Bottles?}

Modern societies are changing and the sciences' character, institutions and functions change with them. From Price's (1963) 'Big Science', via Gibbons and colleagues' (1994) 'mode 2 knowledge production' to Haraway's (1996) technoscience or Nordmann and colleagues' (2011) discussion of the epochal break thesis, from accounts of the universities' new entrepreneurialism and critical discussions of an ongoing projectification of scientific work and its repercussions on the various dimensions of 'epistemic living spaces' (Felt 2009; Felt 2016) to the diagnosis of a 'medialization' of science (Weingart 2012), the sociology of science literature points at an ongoing qualitative change in the scientific system at large, linked to wider societal changes through processes of co-production (Jasanoff 2006). With these accounts of fundamental change comes the necessity to re-evaluate classical conceptions of scientific sociality and identity as they have been promulgated with the emergence of the sociology of science over the past century. Such a re-evaluation is very likely not only faced with shifts in its empirical attention, but also with persisting conceptual weaknesses, ambiguities, even incommensurabilities, and several theoretical turns and diversifications that the field has undergone. In addition, some formerly less contested concepts may have become the battleground of far more fundamental and politically laden conflicts within the wider context of societies at large. One may thus be tempted to simply omit former horizons of analysis

\footnotetext{
K. Kastenhofer $(\bowtie)$

Institute of Technology Assessment, Austrian Academy of Sciences, Vienna, Austria

e-mail: karen.kastenhofer@oeaw.ac.at
}

S. Molyneux-Hodgson

Department of Sociology, Philosophy and Anthropology, University of Exeter, Exeter, UK

e-mail: s.hodgson@exeter.ac.uk 
such as those of (scientific) community and identity, to shelve them as outdated themes in view of these many complicating facets.

This book is dedicated to pursuing another route. Admittedly, the concepts of both 'community' and 'identity' have complex histories, they span multiple social sciences and seem to hit a nerve in contemporary society in a way that complicates their scientific discussion. This situation is not improved by their initial transfer from general sociology to the sociology of science having happened in a seemingly haphazard manner. Nevertheless, our premise is that the study of scientific communities and identities is of enduring importance, evidenced by ongoing, lively research interest as well as science policy initiatives that explicitly target these two dimensions of science and our ambition is to not shy away from a complex and complicated theme. We also hold that to discuss both concepts in relation to each other allows for a deeper understanding.

Our starting point here is to explore new work that addresses community and identity constellations within contemporary techno-scientific environments. On this basis, we ask how we can make sense of conceptions of community and identity in the rapidly shifting contexts in which scientific and technical actors work. What do, or can, 'community' and 'identity' mean in these times of strategic science, transdisciplinarity and identity politicking? What can we gain from discussing both, community and identity, together? Unavoidably, we will thus touch on theoretical weaknesses, unsolved puzzles and societal nerves linked to these concepts. This work can hence only be an effort in initiating-or better-reviving a research programme that is as old as the sociology of science itself. Our central thesis holds that scientific identity and community still matter in many respects, but that they have changed fundamentally during the past decades, in their character, qualities, roles and accomplishments. They have done so alongside shifts in the discourse of science-society relations and with some major modifications in scientific governance regimes. Moreover, we must explicitly acknowledge that changes in scientific communality impinge on options for, and the significance of, identity; and changes in scientific identity constellations impinge on options for, and characteristics of, community.

In this chapter, we begin with an empirical case that we have both encountered, independently, and that has challenged our own thinking, provoking us to re-open the black boxes of 'community' and 'identity' and to re-address their conceptual basis. We then move on to a short delineation of the conceptualisations of community and identity in past sociologies of science. Consecutively, we present the chapters of this volume, their takes on community and identity constellations and effects on the contemporary technosciences as institutions, practices and living spaces. We do so with a focus on common themes that we have pulled to the fore from the various contributions. In a final discussion, we take stock of where our attempt at re-addressing community and identity in contemporary technoscientific contexts has brought us, which ambiguities could not be resolved and which questions seem promising starting points for further conceptual and empirical endeavour. The final assessment of whether the task of filling new wine into old 
bottles is worth the effort, is left to the reader and to the next generation of sociologists of science.

\subsection{Staged Communities, Manufactured Disciplines, and Strategic Identities}

In 2003, the Massachusetts Institute of Technology (MIT) launched a new social format for undergraduate science students to gather, collaborate, and compete; to learn; and to construct, reflect on, and sell their own visionary products. All this took place in the context of a fairly new research area labelled 'synthetic biology', depicted as the rational engineering of biological systems at all levels of hierarchy-from individual molecules to whole organisms (cp. e.g. Serrano 2007). Nowadays, around 6000 people each year-primarily university students-gather in multidisciplinary teams, work on a self-defined project 'to design, build, test, and measure a system of their own design using interchangeable biological parts and standard molecular biology techniques', and present their results at an annual Jamboree- the International Genetically Engineered Machine (iGEM) competition. This annual process is depicted as 'instrumental in the building of the discipline of synthetic biology', 'appeal[ing] to young minds', and 'captur[ing] the attention of industry academics and governments'. In 2017, the iGEM Foundation added an 'After iGEM program', supporting a 'global network' of former participants, including a wider network of advisors and staff that support the student endeavour. In its own depiction, ' $[\mathrm{t}] \mathrm{his}$ global network is leading the field, taking what they learned in the competition and expanding it to continue to build a better world.'

The phenomenon of iGEM has been addressed within science (e.g. Goodman 2008; Smolke 2009; Dixon and Kuldell 2011; Kelwick et al. 2015; Tsui and Meyer 2016) as well as among STS scholars (e.g., Balmer and Bulpin 2013; Damm et al. 2013; Frow and Calvert 2013; Mercer 2015), as has the phenomenon of synthetic biology more broadly. In these works, iGEM is discussed in terms such as: an educational experiment; a medium for the development and sharing of a normative ethos; an extended reflexivity within science; and an essential (or illustrative) part of an ongoing scientific revolution. It is safe to say that the phenomena of iGEM and synthetic biology have become foci of reflection and analysis in both technical and sociological camps, leading to interestingly similar topics and threads of discussion (varying mostly in the amount of critique applied and in the mode of 'reality' attributed to them). Yet, a resolution of what to make of these phenomena is not yet in sight. Do competitions signify an entertaining diversion from the seriousness of the day-to-day business of science (just like the ever-present Gary Larson cartoons in the life sciences' laboratories around the world), a strategy to better cope with sometimes boring routines? Are competitions primarily strategic instruments aimed

${ }^{1}$ All quotations are from: http://igem.org/Main_Page. Accessed 7 July 2018. 
at boosting new hype cycles via new buzzword, mobilising new generations of young researchers and triggering new funding (thus denoting specific constellations in the current science governance regime)? Or are fields such as synthetic biology and their novel interaction spaces emblematic of fundamental changes within identity constellations and the way communality in science is organised and effectuated? And, if so, how will the ways that collectivity and identity are conceived of and organised within science writ large be affected?

iGEM and other new formats of interaction (mobile science festivals, science slams or 'dance your $\mathrm{PhD}$ ' competitions) within and beyond science do-in sometimes very explicit and strategic ways-address aspects of identity and communality, combining a social engineering attitude with a revolutionary emphasis. iGEM is explicitly advertised as instrumental in 'the building of a discipline' as well as in the training and moulding of a new generation of scientists. It does so in a way that differs in fundamental ways from a teacher-disciple-based inter-generational interaction model (Bulpin and Molyneux-Hodgson 2013) or a 'purely academic' educational vision, without denying its didactic and socialising purpose. But rather than only educating future synthetic biologists and establishing such identification with a field, iGEM also aims at producing a global network of former participants. iGEM hence constitutes a consciously designed and staged temporal interaction among peers that elicits lasting identification with the respective event, its participants, and its culture. Moreover it focuses on peer-to-peer interaction rather than intergenerational encounters; on innovation based upon a specific template of parts, actions and interaction patterns rather than on slowly changing disciplinary traditions (with which it aims to break); and on an innovation culture inspired by an idealised atmosphere of friendship-based and fun-fuelled small business incubators rather than a sincere, and serious, tradition-laden ivory tower attitude.

Research fields such as synthetic biology, systems biology, and nanotechnology have each been presented as 'communities to be manufactured' by funding initiatives and science lobbyists alike; by the 'European Systems Biology Community' initiative promoted by the 'Infrastructure for Systems Biology in Europe' consortium $^{2}$ as well as by diverse national funding initiatives that specifically target networking, collaborative projects, or the establishment of temporal, dedicated research centres. But these initiatives do not develop necessarily in ways that lead to a strict identification of individual scientists with these manufactured communities. Attachments to older labels remain strong even when a scientist ventures into new waters (Molyneux-Hodgson and Meyer 2009), often due to concerns about the transitory nature of funding and research policies. Indeed, the next buzzword is likely to be already waiting in the pipeline of science lobbying and funding networks, so that over-identification with an emerging field presents a risk that the label one buys into might not deliver or simply go out of fashion, succeeded by an evernewer label. What can we make of such 'staged' or 'provisional' communities or (labelled) 'communities without members' (Kastenhofer 2013)? Recent examples

\footnotetext{
${ }^{2}$ http://community.isbe.eu/content/what-site-0, accessed 30 September 2019.
} 
such as the iGEM competition, or synthetic biology more generally, challenge our conceptualisation of what the character of communality and identity in contemporary science is and how it is negotiated, organised, and made use of. The concepts invoke or explicitly build upon traditional categories and understandings of 'discipline', 'community', and 'identity', but at the same time call into question the traditional patterns, modes, and reference points of sociality. It is this context in which the analyses presented here are situated.

To date, empirical case studies have addressed such new configurations (cp. for identity, e.g. Calvert 2010 for systems biologists, Felt et al. 2013 for sustainability researchers), while theoretical discussions have highlighted changing conceptions and approaches to communality and identity within sociology and social psychology (Wetherell 2010). Overall, these studies and theoretical debates seem to put forward more questions than answers. They point not only to the idea that the institutional, social, and cultural conditions and conceptions of doing and being in science are shifting (Gläser et al. 2016) but also to as-yet unsolved conceptual ambiguities, inconsistencies, and gaps relating to forms of scientific communality and identity.

With this in mind, our scope and objective for the book must be outlined in the humblest of ways: it does not claim to interrogate, let alone integrate, all existing conceptual approaches nor to solve the many puzzles accompanying current questions of identity and community in science. Rather, the work is dedicated to (1) illuminating selected new analyses of recent empirical phenomena and contemporary heterogeneities relating to community and identity with an emphasis on potential changes within the underlying academic milieu; (2) addressing some of the ways community and identity relate to each other in these contemporary contexts; and (3) indicating how these empirical observations relate to some longstanding theoretical ambiguities and debates. To do so, we have gathered empirical and conceptual studies that can serve as exemplars of the specificity of contemporary constellations within the technosciences and that provide discussion of potential conceptual ramifications.

\subsection{From Communality to Communities-The Socio-Cultural Organisation and Differentiation of Science}

Within the sociology of the sciences, two modes of referring to scientific community are clearly discernible: early scholars like Hagstrom (Hagstrom 1965) explicitly refer to science as $a$ community in the singular-thereby highlighting the communitarian (and thereby social) aspect of science. Such work is 'concerned with the operation of social control within the scientific community, with the problem of discovering the social influences that produce conformity to scientific norms and values.' (Ibid, p. 1) Its result is a 'social turn' in the conception of science, fuelling the emergence of a sociology of science. Later analyses such as Mullins' (1972) famous reconstruction 
of molecular biology's development from a small group of phage specialists to a scientific specialty can be linked to this social conception of science. From there, it seems but a small step to differentiate sub-communities with distinct social and cultural characteristics in the plural — preparing what has much later been labelled as the 'cultural turn' within science studies.

With Hagstrom, the step towards the plural is explained in reference to 'the subcommunities of colleagues within which recognition is awarded' (ibid, p. 2). Its methodological counterpart consists of a multi-disciplinary empirical sample, including 'established' and 'new' disciplines, disciplines in which the 'exigencies of research require some formal organisation' with disciplines without such exigencies (ibid, p. 4) - a methodological choice that hints at an a priori idea about a sociocultural differentiation of science into disciplinary (sub)communities and (sub)cultures. But other than the reference to science as a community in the singular (or Merton's science as a social institution and Polanyi's science as a republic, to add just two further renowned examples), the reference to science as a collection of subcommunities or subcultures not only comes with a plural, it also comes with less conceptual consideration about the character of the social entity these (sub)communities or (sub)cultures represent. ${ }^{3}$

As with Hagstrom (1965), the later spike in interest on cultural aspects of science within STS was based upon the theoretical assumption as well as the methodological sine qua non that different cultures co-exist and can be compared on empirical grounds, necessitating the existence of specific social entities that exhibited this cultural plurality and could be studied case-by-case, without theorising the underlying socio-cultural differentiation in detail. Fleck (1983 [1974])—as one prominent forerunner of the cultural turn within science studies-introduced the notions of thought style and thought collective, building on a psychology of perception rather than a socio-epistemological perspective and leaving some essential questions to mere statements, such as the assumption that one can be a member of plural thought collectives. Other early science studies scholars focused on national scientific styles (Jamison 1997) with a focus on the history of scientific ideas. Scholars like Harwood (1993) or Knorr-Cetina (1999) have reconstructed isochronic 'styles of scientific thought' or 'epistemic cultures', whereas scholars like Pickstone (2001) or Hacking (2002) have delineated 'ways of knowing' or 'styles of scientific reasoning' in an attempt to develop a historical epistemology (Kusch 2010), but have stayed fuzzy enough about the related social dimensions and entities. ${ }^{4}$ With an edited volume on the 'regional and national configurations of research fields', Merz and Sormani (2016a) provided fundamentally new insights into the socio-political dimensions of localised styles.

\footnotetext{
${ }^{3}$ The specificity of scientific communities in comparison to other communities has been highlighted and extemporised in scholarly work on epistemic communities (Meyer and Molyneux-Hodgson 2010) or 'wissenschaftliche Produktionsgemeinschaften' (Gläser 2006).

${ }^{4}$ Historical accounts of (fundamental) change thus culminated in a seemingly unsolvable debate about the validity of the accompanying epochal break theses (e.g. Nordmann et al. 2011)—maybe because the institutional dimension had been unaddressed.
} 
Thus, scientific communities as socio-cultural phenomena are constantly, if indirectly, addressed as reference points for a socio-cultural diversification in the scientific production of knowledge. How the social unit of these cultures should be conceived of and how the individual relates to such styles, collectives, and cultures often remains implicit. Specialities, scientific fields (Whitley 1984), disciplines, university departments (Becher and Trowler 2001) or novel types of science centres (Hackett and Parker 2016), invisible colleges (Crane 1972), or transepistemic arenas (Knorr-Cetina 1982), opposing politicised networks (Haas 1992, 1994; Bonneuil 2006; Böschen et al. 2010) or Scientific/Intellectual Movements (Frickel and Gross 2005; Parker and Hackett 2012) figure as potential suspects to locate and generate diversity. ${ }^{5}$ The relation between culture, style, or collective and the individual scientist has also been resolutely fuzzy. Over a certain period, studies of socialisation, enculturation, career tracks, collaboration, and membership aimed to link individuals and their respective collectives. Communities were depicted as effectuated by academic socialisation, academic institutions and research practice, while at the same time being constitutive of the latter (Becker et al. 1961; Liebau and Huber 1985; Traweek 1988; Wenger 1998; Becher and Trowler 2001; Beaufays 2003; Arnold and Fischer 2004).

But the more science studies lost interest in the individual as a central site of epistemic action and focussed more on conditions, contexts, networks, actornetworks, and hinterlands, the less salient these themes became. Questions traditionally raised by social psychologists or anthropologists lost momentum. With more recent empirical examples of technoscientific convergence and transformation in the realms of nano-, bio-, info- and cogno-engineering, the disciplinary nature of these phenomena has been called into question on empirical rather than theoretical grounds, rendering disciplinary categories as proxy even less attractive than previously and putting the mode of communality they represent up for discussion (Frickel 2004 on genetic toxicology; Kastenhofer 2013 on systems biology; Lewis and Bartlett 2013 on bioinformatics; Balmer et al. 2016 on synthetic biology; for a general discussion, see also Weber 2010 and Merz and Sormani 2016b). Waves of digitalisation, projectification, massification, mediatisation and new public management seem to overrun scientific institutions, and the significance of scientific community and specialty communities is once again called into question. Concurrently, calls for the active building and shaping of specific kinds of communities arise

\footnotetext{
${ }^{5}$ In Merton's case, it is the disciplinary layer that is referred to as proxy for a relating social entity. Many other scholars go down the same road without really explicating this choice of proxy: Fleck's (1947/1983) thought collectives are illustrated in reference to disciplines; Knorr-Cetina in her work on epistemic cultures (1999) chooses her empirical cases on a (sub)disciplinary basis-comparing 'molecular biology' with 'experimental high energy physics' - and bases her argumentation heavily on these categories. While she does aim at going beyond a disciplinary ontology, 'replacing notions such as discipline or specialty with that of an epistemic culture' (ibid, p. 3), the (sub)disciplinary categories remain central points of reference in her reconstructive work. Many ensuing empirical studies have aligned with this pattern of taking disciplinary categories as a proxy for social units of cultural differentiation in their methodological approach and argumentation.
} 
within science policy, taking for granted that we need communities, and 'functional', 'interdisciplinary', 'ethical', and 'responsible' ones at that. While analysts proclaim an era of 'communities of promise' (Brown 2003) that coalesce around the promotion of distinct technoscientific visions or utopias, science policy seems to fully buy into the 'promise of communities'. ${ }^{6}$

\subsection{The Scientific Persona and Identity}

Against the background of general shifts within science and with the more specific shifts adhering to the dimension of scientific institutions and communalities, the theme of scientific identity also comes into play. Any conception of scientific community speaks to a certain conception of identity: an identity that comes with being a member of a community, an identity that is constructed, provided and experienced within a community, or as an identity shared, a communality that forms the basis of a community. Questions of identity thereby stretch from the identity of science at large (e.g., Weingart 2003), to questions related to the scientific identity of its personae (Daston 2003, see below), and to questions of disciplinary or other more specifying identities of scientists. They also encompass questions about local differences or historical shifts in the quality and momentum of identification, denoted by terms such as 'provisional identities' (Ibarra 1999) or 'liquid identity' (Bauman 2004).

If the theoretical as well as empirical feasibility of community as a concept is being drawn into discussion in our work here, the challenge posed is even greater for the conceptualisation of identity. Margaret Wetherell in her elegant introduction to the field of identity studies thus summarised:

Nearly every scholar who works on identity complains about its slippery, blurred and confusing nature. Identity is notoriously elusive and difficult to define and nearly every generation of scholars since the 1950s has included some keen to dismiss it as a consequence, concluding it has no analytic value or purchase. (Wetherell 2010, p. 3).

She goes on to delineate the various paths identity research has taken, from a focus on identity as a subjective individual achievement or as social subjectivity, to identity as linked to group membership and belonging or identity as an ethical and political category. She outlines deconstructions and critique of the concept and category on theoretical, political, and empirical grounds. Still, Wetherell comes to the conclusion that identity should not be discarded as a concept within the social sciences:

In my view, identity continues to be good to think with precisely because of the features which some have found difficult and irritating: the long chronology, the accretion of many layers of meanings, the rich sweep, the heated debates, the constitutive ideologies, fantasies and fictions, the politics, and the very many ambiguities. (ibid, pp. 23-24)

\footnotetext{
${ }^{6}$ Originally put forward within the analytical as well as managerial framework of 'communities of practice' (Wenger 1998).
} 
There are rich seams of research on scientific identity in sociological and anthropological traditions, alongside the (social) psychological take of Wetherell and colleagues (e.g. Jenkins 2014). Yet identity has been less frequently referred to in explicit terms in science studies, although some scholars have linked issues of identity with issues of disciplinarity and disciplinary socialisation. ${ }^{7}$ The questioning of the disciplinarity of contemporary sciences has come with a perceptible rise of studies scrutinising and problematising disciplinary identity (see, for instance, Kurath and Maasen 2006, Kurath 2010 or Chari et al. 2012 on disciplinary identity within nanoscience and toxicology; Calvert 2010 or Osbeck and Nersessian 2017 on disciplinary identity within systems biology). Further effects of such a problematisation of disciplinary identity on the individual as well as the systems' level are scarcely discussed.

Another route to addressing identity in science studies has been linked to an interest in the scientific persona. Lorraine Daston coined this field of interest (Daston 2003; Daston and Sibum 2003; Daston and Galison 2007), depicting the scientific persona as a link between individual biography, scientific institutions, and society at large. The field has recently developed with a primarily historical focus (e.g. Paul 2016) and with a focus on the moral dimensions of being a scientist in various sociohistorical contexts (e.g. Shapin 2008). While disciplinary differentiations gain less attention, an aim to better understand contemporary conditions of being in science is a clear motivation of this historical enterprise. It is closely related to analyses of 'academic identity schisms' that go with contemporary shifts in the organisational culture(s) of higher education institutions (Henkel 2000), such as those between an academic identity and a managerial identity (Winter 2009). Also in this corpus of literature, values and norms play an important point of reference.

Furthermore, the strategic dimension of staging one's own disciplinary identitya dimension introduced already by Gieryn's (1983) account of the instrumentalisation of a scientific identity within strategic boundary work-has been re-invoked against contemporary post-disciplinarity or new disciplinarity (Marcovich and Shinn 2011). In recent studies, identity is once again framed as a medium of strategic positioning, but also as a medium of experimentation, highlighting the discursive construction of identity, rendering identities provisional (Ibarra 1999), contextual and multiple. The strategic account is thus combined with an account of fluidity, resonating with what Bauman has put forward as aspects of a 'liquid modernity' (Bauman 2004).

When it comes to discussing how scientific community and identity are linked to each other, how they are co-produced and how they reverberate, the sociology of science literature does not provide a lot of material. The mostly implicit take that both scientific community and scientific identity are heavily based on disciplinary categories does not further this matter and every conception of community, every take on identity will come with its own explicit or-in most cases-implicit take on

\footnotetext{
${ }^{7}$ Again, similarly to how community has in many cases been linked to disciplinarity in empirical studies.
} 
how these two aspects of scientific life are (or should be) linked to each other. With fundamental shifts in science and society, both aspects seem to change gradually and simultaneously in many respects, in their quality and in the ways they come to matter. Both terms seem to now denote an outdated era of 'the scientific life', an era that maybe has only existed as an ideal type all along, when at the same time these very terms are rediscovered as levers for socially engineering science and-more importantly-its outputs in quantitative and qualitative terms.

In some respects uniting community and identity spheres, studies of academic socialisation (enlisted exemplarily in the previous section) and 'community of practice' thinking (Wenger 1998) can be described as a middle ground, escaping overly deterministic structural frameworks and moving beyond narrowly localised moments of interaction as a means to describe and explain. They take practice-based theories as a point of departure in understanding how communities coalesce around what people do together and the common resources and meanings they (re-)produce in the process. An important element is that learning and collaboration are the key mechanisms through which community membership, belonging, and identities are gained and engendered. Communities, their representatives and practitioners are thus co-produced. Identity formation is positioned as an important element in learning and collaborative practice,

[b]ecause learning transforms who we are and what we can do, it is an experience of identity. It is not just an accumulation of skills and information, but a process of becoming-to become a certain person or, conversely to avoid becoming a certain person (Wenger 1998, p. 215).

The emerging sociological work on 'epistemic communities' is also instructive in bringing together distributed, relational, and 'networked' aspects of community formation with a focus on the experiences of participation and the formation of individual identities. The notion of epistemic communities draws attention to the practices through which communities are produced together with their practitioners as 'site[s] where knowledge standards and practices are being negotiated, and a sense of belonging and researcher identity is being defined' (Lorenz-Meyer 2010, p. 8). Similarly, Meyer and Molyneux-Hodgson (2010, p. 5) propose probing how the connections established in building new epistemic communities 'shape, demarcate and articulate identities of present and future knowledge producers, and the individual and collective trajectories on which the latter navigate'. The prevalent politically-framed understandings of scientific communities and identities remain overly consensual. The policy-directed formation of new communities and identities remains conceptually too simplistic, leaving relating interventions ineffective at best. Thus, "how a community comes to be assembled...the work, the politics, the materialities, the identities, the uncertainties that go into the formation and maintenance of a community clearly deserve our attention' (ibid, p. 1). The papers in this volume clearly respond to this invocation. 


\subsection{Synthesising Communities: Processes of Qualitative Change, Heterogeneity, Theoretical Demarcation and Social Engineering}

The chapters in the first section illustrate a range of conceptualisations of the phenomenon of collectivity and do so from four directions: (1) they focus on processes of qualitative change of collectivity over time and thereby elucidate specific stages; (2) they zoom in on the heterogeneity of members, roles, and identities of communities; (3) they raise the question of which terms and concepts best enable empirical analysis of collectivity, moving towards a demarcation of community from other social formations and for a distinction in specific cases of community; and (4) they relate to avenues for socially engineering science and its output. Although these four themes are closely connected, the individual chapters provide a specific empirical case and a specific primary focus that elaborate on each theme. The empirical cases cover the transnational emergence of synthetic biology (Raimbault and Joly, Degelsegger-Márquez, Blümel), the local emergence of a field (supramolecular chemistry) (Noël), a regional cluster on microbial biofuel production (Cointe), international collaborations in nanotechnology (Ulnicane), engineering laboratories in the United States (Wylie), and communities of European eGovernment practitioners (Jarke).

\subsubsection{Processes of Qualitative Change}

Mullins' (1972) analysis of the development of molecular biology as an institutionalised scientific specialty between 1935 and 1972 along a four-stage process, starting with a loose paradigm group, and undergoing intermediate stages of a rapidly expanding communication network and a dogmatic cluster, still serves as a point of reference when processes of field emergence are addressed by sociologists of science, especially so in the empirical context of the biotechnosciences. Others may have criticised, refined, or replaced Mullins' model, but the general ambition to combine a focus on historical stages with a characterisation of corresponding social entities has not lost its momentum. It has only recently been revived by the analysis of the emergence of new technoscientific fields as Scientific/Intellectual Movements (Frickel and Gross 2005; Parker and Hackett 2012); an approach applied by scholars like Vermeulen (2018) to phenomena such as systems biology, 'discuss[ing] three different movements in the emergence of systems biology: aggregation, circulation and oscillation' (ibid, p. 1766).

Marianne Noël, in her historical reconstruction of the emergence of supramolecular chemistry in Strasbourg in the second half of the twentieth century, draws on Mullins' approach. Like Mullins, she combines an analysis of intellectual and social characteristics. Based on the publication profile of a central figure, the French chemist Jean-Marie Lehn, she develops three periods that resonate with, but do not 
totally conform to, Mullins' stages. They comprise the emergence of the paradigm, the emergence of the specialty, and the institutionalisation of supramolecular chemistry. Her argument also hints at a broader paradigm shift within chemistry that not only inspired the emergence of supramolecular chemistry (in line with Mullins' account) but also became normalised parallel to its establishment. Noël mentions that Lehn at the height of his career founded a journal. Rather than calling it 'Journal for Supramolecular Chemistry', he decided on 'Chemistry: A European Journal'. This choice can be interpreted as denoting at least two moves: one to frame the supramolecular paradigm not as an addition to existing chemical stances but as a now ubiquitous standpoint in all of chemistry; and another one to posit this ubiquity of the supramolecular paradigm in chemistry as a potentially European approachcreating space to envisage a 'European school of chemistry' - that could be populated by Lehn, his network, and his legacy (we will return to the concept of 'research schools' and 'local differentiation' later). This story of institutionalisation culminates with the creation of the 'Institut de Sciences et d'Ingénierie Supramoléculaire' (ISIS) and the design and realisation of a dedicated building. The institutional and architectural organisation, expressed by the label of a 'research hotel' (hotel à projets), becomes emblematic of a specific style of organising science, of envisioning a specific notion in scientific career patterns, and of engineering sociality in science.

An interesting difference between the formative analyses of Mullins' generation of scholars (including 'finalisation theory' put forward by the Starnberg group, Böhme et al. 1973) and current work within the sociology of science is that the former emphasised a final, 'mature' climax whereas today scholars are more fascinated by the seemingly frozen states of emergence of the contemporary technosciences. In line with this contemporary take on the theme of historical change, processes of community formation are mostly studied as phenomena of (ongoing) emergence in this volume's further case studies. The idea of a potential halt to this process at a future 'mature stage' may lurk in the background of some analyses, but as Molyneux-Hodgson and Meyer noted (2009) the question of whether a community ever stabilises is firmly on the table.

Clemens Blümel's contribution to this volume illustrates this stance well. Based on an in-depth, multi-method analysis of review articles in synthetic biology published between 2002 and 2012, he reconstructs three differing types of reviews that concur with different historic periods. The first set are highly cited and closely linked via cross-citation. This type of article is then replaced by narrative accounts of the history of synthetic biology from 2007 onwards that provide a larger structure within which events are located. These articles put 'heroic objects' at centre stage rather than foundational fathers or spokesmen (c.f Abir-Am 1985 on molecular biology). The third, evaluative, type of review is most frequent post-2010 and highlights application of the science. Overall, Blümel sees a shift from authoritative to narrative forms of constructing a field that aligns with a narrative normalisation achieved and represented by joint histories. One could also depict this shift as one from prophets to apostles. Some congruence with Mullins' paradigm group, communication network, cluster, and institutional stages or with Stent's (1968) romantic, 
dogmatic, and academic phase can be postulated perhaps. In contrast to earlier publication analyses (especially Bastide et al. 1989), Blümel highlights that a large quantitative share of review articles signals field emergence rather than field maturity in his case; field maturity is signalled by a distinctive (narrative or evaluative) type of review article.

Benjamin Raimbault and Pierre-Benoît Joly provide a further reconstruction of synthetic biology's emergence but focus on specificities of this emergence phase rather than on its (inevitable) obsolescence and hence point towards a conceptualisation of and interest in emergence as a 'perpetuated state' or 'end in itself'. Contributing to a new political sociology of science (cf Frickel and Moore 2005), the authors reconstruct this process by means of a multi-sited ethnography as well as scientometric accounts, zooming in on actor constellations (with reference to Latour's Actor Network Theory) and field characteristics (with reference to Bourdieu's field theory and to strategic action fields, Fligstein and MacAdam 2012). The approach puts power constellations and rules governing legitimate action at centre stage and acknowledges not only internal factors such as scientific credibility but also external ones like societal relevance. The authors thus frame 'the emergence of a techno-scientific field as a multiscalar and progressive establishment of a new set of epistemic and social rules' (p. 102). They define three determinant dimensions of this emergence: heterogeneity across the emerging community (of disciplines, research questions, visions, and social norms), which they see as constitutive of the process of emergence; hierarchy (between a core-group and peripheral members or temporary visitors) with strategic alliances; and autonomy, which in the case of synthetic biology is closely tied to its links to industry (and potentially also to science policy). We will return to all three dimensions below when we address the idea of heterogeneities.

In the context of reconstructing qualitative change at the level of research projects, Béatrice Cointe provides an enlightening analysis of how a distinct research project - an interdisciplinary project on potential avenues for biofuel production in microorganisms, funded in the form of a regional excellence initiative and excellence cluster-fares in and impacts on the (local, existing) research community. She thus re-constructs a 'project-ed community' as a local community that undergoes an instance of projectification just as much as its making or intensification is the envisioned outcome of a project. What the project 'really is' and what processes it entails, is revealed to be ambiguous, multifold, and fuzzy in the author's analysis, based on an in-depth participatory ethnographic study. In her final diagnosis, she depicts the project as 'an experiment in community-making: a nutrient broth. ..in which some collaborations may thrive while others barely catch on' (p. 140).

A similar point is addressed by Inga Ulnicane in her contextual comparative analysis of two international research collaborations in nanotechnology; one a 'bottom-up' initiative emerging from informal relations between individual scientists, and the other initiated by a funded European Commission framework programme. Her empirical material comprises publications; citations; organisational, project, and CV data; interviews; and protocols from site visits. In her resulting 'tale of two scientific communities' she reflects on differences and similarities in 
the dynamics of academic self-organisation versus external steering of research collaborations (thereby implicitly upholding an ontology in which science funding is external to science). To describe the dynamics of research collaborations she refers not to a linear evolution of the emergence of scientific fields or communities but rather to a circular movement: her model of collaborative processes features recurring phases of emergence and renewal, formal collaboration, informal collaboration, and scientific output.

Marianne Noël discusses some aspects of the emergence of supramolecular chemistry in reference to Marcovich and Shinn's (2011) 'new disciplinarity'. She thereby refers to recent discussions about the explanatory power of the category of disciplines within the sociology of the sciences. On the one hand, this category has been historised lately, reframed as an emerging property of eighteenth and nineteenth century continental European science only, and hence not necessarily valid for other local or historical contexts. On the other hand, scholars challenged the assumption that disciplines constitute a primary ordering category for all phenomena or all practical contexts relevant for the sociology of the sciences. Notwithstanding all this critique and relativisation, it was not only the first generation of analysts of emergent social entities in science that was dedicated to the emergence of disciplines (cp. Lemaine 1976); the reference to disciplines as an ordering category within the science system still abounds today, in scientists' accounts as well as in sociological literature. Many of the contemporary alternative conceptions such as interdiscipline (Frickel 2004, Weber 2010), post-normal science (Funtowicz and Ravetz 1992), or Mode 2 (Gibbons et al. 1994) are based on the idea of a precursor situation in which disciplines were central and would not work without this reference (just as postmodernity is tied to the preceding conception of modernity or technoscience builds on a preceding conception of modern science). In many instances, the reference to disciplines is also under-theorised, with the category being used as a proxy for any social or institutional differentiation related to scientific content; a fate very similar to that of the category 'community'. Carlos Cuevas-Garcia, in the second section of this volume, provides another sketch of the fate of the disciplinary category within the sciences, depicting disciplinarity as a 'widely taken for granted ideal from the Nineteenth century onwards', with disciplinary boundaries being to some extent illusionary, 'but real in their consences.' (p. 151)

As noted above, Béatrice Cointe embeds her analysis in a general observation of an ongoing projectification in science. According to Felt (2016), projects are nowadays a 'key organizing principle into science'. They co-organise day-to-day scientific work and international collaboration as well as the practice of science policy. Just as many other contemporary organising parameters (like the local and regional clusters as described by Bettina Bock von Wülfingen and Marianne Noël or the emerging fields of synthetic biology and nanotechnology addressed by Benjamin Raimbault and Pierre-Benoît Joly, Clemens Blümel and Alexander DegelseggerMárquez in this volume), projects bring together actors across teams, countries, disciplines, and actor fields (such as science, policy, industry, and society). They thereby 'often embed research in extra-scientific financial, societal and political concerns, echoing (and maybe institutionalising) Knorr-Cetina's "transepistemic 
arenas of research" (1982) introduced as a critique of analyses focusing on "specialty communities" (Cointe this volume). The author also refers to 'umbrella terms' (Rip and Voss 2013), another observational category demarcating fundamental shifts in the contemporary scientific system. And just as with projectification, the phenomenon of the 'umbrella term' is closely linked to changes in the quality and influence of the funding regime with which the science system is currently confronted. Accounts of 'perpetuated emergence' (Kastenhofer 2016) or of implementations and effects of new public management approaches at universities add up to such diagnoses of post-modernity within academia (Rip 2004). And just as with the discussion surrounding the 'new disciplinarity', the thesis of an 'epochal break' (Nordmann et al. 2011) lurks in the background without being decisively answered. Addressing this would be a perfect contribution to 'a more deeply historicised sociology of scientific knowledge' (Hess 2005). In this volume, a related question is: are there fundamental shifts in the conditions, qualities, and relevance of communality and collectivity in science? While no single contribution in this volume will be able to answer this question, all of them contribute new ideas to the discussion.

In all the analyses, change is configured as something that needs extra force, while stability is treated as the likely default historical avenue. It is all the more important to mention here that a focus on practices brings to the fore the constant need for enactment in both change and stability. Such a practice-oriented approach is followed not only by some of the chapters focussing on identity but is also central in analyses of performed communities, probably most visibly in Juliane Jarke's account of 'communities by template'.

\subsubsection{Heterogeneities}

Leaving aside the proximal, short, medium, and long-term historical foci of the chapters, accounts of heterogeneity can also be found at the isochronic level. These discussions confront a naïve conception of scientific communities in which such communities are made up of identical members. The naïve position can result implicitly from studies that only compare the 'comparable', e.g. focussing on one subgroup of a community: students throughout the socialisation process; Principle Investigator accounts in a series of interviews; or core figures as authors of influential articles. Rarely are such implicit conceptions of community confronted with a theoretical relativisation. The chapters of this volume, however, point towards several kinds of heterogeneity: communities are heterogenous with respect to their members' career stages (Wylie); the roles their members exhibit (Raimbault and Joly); and prevalent paradigms and associated sub-communities (DegelseggerMárquez). Moreover, scientific collectivities like those realised by research projects encompass diverse alternative realities (Cointe).

Caitlin Donahue Wylie's contribution to this volume on 'how undergraduate students contribute to engineering laboratory communities' puts heterogeneity and 
the related issue of a community's ontology centre stage: who do we as sociologists of science configure as part of a community? Who takes part in co-shaping it? Who is indispensable in sustaining it? These questions touch on issues of membership, be it of symbolic or practical nature, from an internalist or analytical perspective. Wylie's account focuses on the-often downplayed - role of students within a laboratory research group and acknowledges their centrality in day-to-day research practice and in the shaping of research projects and research programmes. The two laboratories studied are involved with the engineering of material properties and electronic sensor systems at a 'medium-sized public research university in the United States'. Beyond classical socialisation studies, the author frames students not only as future members of a community but also highlights that such 'novices bring important aspects to a community' such as open-mindedness, multi-disciplinary skills, and knowledge. Her account gives a sense of the adventurousness that students can contribute to a research laboratory ecosystem and goes on to show how students influence research and thereby 'actively contribute to the construction of knowledge and communities.' Interestingly, she also notes that novices can fulfil this function precisely because they are 'situated at the periphery', providing 'a wisdom of peripherality' (Wenger 1998, p. 146, this volume).

The focus taken by Wylie on student positioning confronts a challenging theoretical situation, and the conceptual aspects are far from being fully realised. Nevertheless, the centrality of the theme-especially within contemporary technoscientific contexts-is difficult to ignore, especially when carefully reading through the other chapters of the volume. Whereas Mullins (1972) refers to students only indirectly, as 'being a student of' someone, in some of this volume's chapters, the functions that graduate and $\mathrm{PhD}$ students fulfil —even before they are acknowledged members of academia - occur again and again. In Noël's account of supramolecular chemistry's emergence, interviewees stress how much they 'tried to interest graduate students' in a specific phase of field formation and how much they 'insisted that several postdoctoral co-workers enter the field'. In Ulnicane's analysis of two nanotechnology collaborations, joint $\mathrm{PhD}$ students are central in launching and stabilising the international networks. The $\mathrm{PhD}$ phase entails career risks and precariousness as well as distinct institutional demands (namely to enrol at a university accredited for the supervision of $\mathrm{PhDs}$ ) and norms (namely to demonstrate international mobility), as does the postdoc phase (namely the institutional demand to apply for an open, paid position and to demonstrate expertise and success on an international scale), all of which demand or at least encourage international mobility in the cases she studied. As a result, she observes that 'both collaborations were launched by internationally mobile early career researchers' (p. 113). Conversely, a collaboration can also come to an end when people move to other sites during their highly mobile early career stages. It was the novices that strengthened inter-group ties via short visits 'to learn techniques and join experiments' and ensuing fellowships. Just like Wylie, Ulnicane notes that PhD students ask questions and thereby foster interdisciplinary dialogue, changing the quality of the interaction. Moreover, the motivation 'to give $\mathrm{PhD}$ researchers an opportunity to present their work, learn and find opportunities' for future jobs was depicted as a central element of the projects. 
The project level was also seen as especially important to these novices as it 'lends visibility and group identity to young scientists'. Projects allow for 'communication and collaboration across all levels of hierarchy', while getting support from the organisations' top levels.

The focus on novices demonstrates that communities are stratified, not homogenous; they consist of diverse members and roles. Heterogeneity of roles and fields is addressed in exemplary fashion by Raimbault and Joly. With reference to Fligstein and McAdam's conception of strategic action fields (2012) as

a constructed mesolevel social order in which actors interact with one another on the basis of shared understandings about the purposes of the field, relationships to others in the field (including who has power and why), and the rules governing legitimate action in the field (ibid, p. 9)

they stress the importance of distinct roles within a field. With reference to Mullins' (1972) model, Crane's 'invisible college' (1972), Collin's 'core set' (1981), Frickel and Gross' (2005) role differentiation of high status scientists, networks and young scholars, and Fligstein and McAdam's (2012) depiction of incumbents and challengers, they set the scene for their own discussion of various roles within the emergence of synthetic biology and relate this to the dimension of 'hierarchy'. They come close to devising roles distinct to the subfields, clusters, or discourses within synthetic biology that can be adopted. Their scientometric analysis hence results in a differentiation of the field into four clusters: biobrick engineering, protocell creation, genome engineering, and metabolic engineering (cf O'Malley et al. 2008). These four clusters are positioned in different ways, fulfil different roles, and face different fates throughout the history of the field. Their characterisation evokes a visionary role for biobrick engineering, whereas metabolic engineering fulfils the role of delivering applications. With reference to a further dimension, namely 'autonomy', they discuss roles exhibited by non-scientific fields, as emerging fields 'have a Russian doll structure', intertwining the micro-, meso-, and macro level and rendering seemingly internal/external interactions key components of emergence processes. This is a depiction that comes close to Knorr-Cetina's conception of transepistemic arenas-a notion also strengthened in Cointe's contribution. 'Autonomy' thus refers to autonomy from other fields rather than autonomy from extra-scientific contexts. An analysis of the core-group of synthetic biologists reveals that most of these are affiliated with the biobricks approach, based in the US, and have close ties to business development—depicting remarkable homogeneity within a heterogenous and changing context.

Heterogeneity of roles is also addressed in Blümel's contribution: the shift from authoritative to narrative forms could also be depicted as a shift from prophets to apostles. Mullins (1972) referred to an earlier role differentiation put forward by Ben-David and Randall Collins in the context of a field's emergence, namely: forerunners, founders, and followers (Ben-David and Collins 1966). Mullins' own model devises roles only indirectly, such as the charismatic (or dogmatic) role detrimental in the cluster phase. Indeed, according to Mullins (1972, p. 79), 'leadership and charisma may be the most important factors [during the cluster phase], much more important, for example, than accuracy in intellectual judgement.' Blümel replaces the charismatic or heroic founding figures central to Mullins and others' 
(Abir-Am 1985) earlier accounts with 'inaugural devices as heroic objects'. He thus relocates the (narrated) centre of activity and actor-ship within contemporary phenomena of field emergence, again raising the question whether the fundamental logics of the empirical phenomena we observe in science have changed or whether it is primarily our interpretive sociological frame that undergoes changes over time.

Heterogeneity of paradigms resulting in sub-differentiation in the emerging field of synthetic biology is addressed by Raimbault and Joly and by DegelseggerMárquez. The latter points to a differentiation into an orientation towards understanding along an epistemic paradigm on the one hand and an orientation towards construction along an engineering paradigm on the other hand with references to earlier work by other scholars (Kastenhofer 2013; Ramibault et al. 2016). As a result, he doubts that the field will ever represent a disciplinary community-a question first posed by Molyneux-Hodgson and Meyer (2009) a decade ago-and characterises it rather as an interdiscipline with 'porous epistemic boundaries and temporal forms of institutionalisation', perhaps even limited to specific national environments like the UK.

Heterogeneity in the isochronic perception or construction of one and (arguably) the same object-in this case a project-is also a main concern in Cointe's case study. What the project really is about, what its boundaries are, who and what belongs to it, is processed differently and with different results in three parallel 'versions' of the project and its collective. The author thus analyses three versions of a 'project-ed community': as an argumentative device in its documents; as a strategic venture in its institutional arrangements; and as an arena for scientific work in its daily research activity. These avenues 'provide different, but coherent pictures of the project-ed community', though the version of the project as an arena of research appears fuzzier than the other versions- 'it turned out to be quite elusive as a whole in practice' as it was not always clear who or what was (an enduring) part of it and who or what was not. Thus, 'projects are more than temporary arenas of research, they are also argumentative devices that justify and display excellence and relevance, they serve to imagine future research communities and to start building them', they represent 'strategic entities that integrate scientific practices into coherent narratives to further the interests and ambitions of various parties', they are 'an experiment in community-making: a nutrient broth in which some collaborations may thrive while others barely catch on' (as also illustrated by Ulnicane). In short: projects exhibit versatile functions. In a similar vein, Degelsegger-Márquez characterises synthetic biology not only as a (heterogenous) field or an interdiscipline but even more so as 'a set of community-making devices' (a term originally developed in Molyneux-Hodgson and Meyer 2009), offering two alternative understandings and co-existing in distinct dimensions. 


\subsubsection{Theoretical Demarcations}

The accounts we have provided above of qualitative change over time and isochronic heterogeneities in scientific collectives touch on the conceptual question of what kind of social entities we speak when referring to 'scientific communities'. Although all chapters refer to this label, evidently not all chapters address the same phenomenon. This becomes visible in alternative denominations such as (paradigm) group, (project) team, collaboration, network, cluster, field (as in 'hot field' or 'emerging field'), specialty, and discipline or by further specification such as 'community of practice' (Wylie and Jarke in line with Wenger 1998), 'project-ed community' (Cointe), or 'community of knowledge application' (Degelsegger-Márquez). Some authors content themselves with a loose or implicit definition of collectivity, others confront the theoretical discomfort head-on. The latter approach displays an interesting diversity, as we now elucidate.

Alexander Degelsegger-Márquez' contribution explicitly refers to early classical definitions of community within the sociological literature, that is, to authors like Ferdinand Tönnies, Max Weber, and Talcott Parsons. Within this context, 'community' is defined in contrast to 'society'. In this kind of conception, individuals are born into communities and realise all their actions and social relations within them. Strong social ties building on (diverse) personal interactions, roles, values, beliefs, and subjective feelings are emphasised. Performing community is characterised by affectivity, functional diffuseness, particularism, valuation by ascription, and an orientation towards the collective. It is opposed to affective neutrality, functional specificity, universalism, valuation by achievement, and orientation towards oneself. The tensions of this classical understanding of community with the modern framing of science are more than obvious; a tension that later spurs the radicality of Hagstrom's or Kuhn's thesis that the science system also exhibits characteristics of a community. Merton's scientific ethos (1993 [1942]) can be understood as presenting an intermediate position: science does follow an ethos (which points towards the quality of a community), but this very ethos is to mostly not follow the classical logics of a community (especially with the norms of universalism and organised scepticism). Degelsegger-Márquez sketches recent conceptualisations that frame communal aspects of science as a distinct kind of communality, namely one that is oriented towards the production of knowledge (Gläser 2006). As with Merton, the resulting conception of community is bounded: such scientific 'production communities' are tied to a function; they represent 'the mode of social organisation that allows scientists to produce ... scientific knowledge'. In a further step, the author introduces theses of qualitative heterogeneity and/or change in science, referring to Elzinga's (1993) hybrid epistemic communities driven by rationales from policy-making or commercial application, Frickel's (2004) interdisciplines characterised by porous boundaries and a collective interest in problem-solving, and the proliferation of the engineering approach in the sciences along a technoscientific paradigm leading to the hybrid constellation of 'techno-epistemic communities' and a stratification along techno-epistemic visions rather than 
disciplines ('communities of vision', Kastenhofer 2013, p. 133). From this, the author devises his own concept in close reference to the aforementioned literature, namely that of a 'community of knowledge application', based on his own empirical material on the case of synthetic biology undertaken between 2008 and 2016). This concept explicitly acknowledges the formative impact of a strong practical and/or visionary focus on the utilisation of research output within non-epistemic contexts. Degelsegger-Márquez relates this to an observable difference between communities of knowledge production and communities of knowledge application, and sees only the latter realised within the field of synthetic biology: 'Under the umbrella term synthetic biology, we observe researchers sharing views on knowledge application while differing in their outlook on knowledge production (p. 178).'

Thus, in Degelsegger-Márquez' contribution the tension of a proclaimed community of synthetic biology against the background of epistemic heterogeneity is dissolved by the delineation of a community of knowledge application. The outlined tension between early sociological conceptions of community and later conceptions of scientific communities within the sociology of the sciences-or more broadly speaking, science studies - stays unresolved. Other chapters add further theoretical foundations to discussion of communities in science. Cointe refers to various contemporary scholars exhibiting the common trait 'that they are not primarily based on disciplines and often embed research in extra-scientific financial, societal and political concerns'; an argument that comes close to Raimbault and Joly's account of synthetic biology, albeit not explicated by these authors. They enlist Latour's Actor Network Theory as well as Bourdieu's classical field theory and Fligstein and McAdam's theory of strategic action fields. Thereby, a focus on arenas and networks stands in some tension to a focus on (the emergence of) distinct social entities, such as Bourdieu's scientific fields. Noël's strong reference to Mullins' four stage model also builds on different patterns and roles of communication, co-authorship, apprenticeship, and colleagueship but leads to the characterisation of a distinct specialty, just as Stichweh's disciplinarity and Marcovich and Shinn's 'new disciplinarity' emphasise 'disciplines as stable referent of practitioners, providing the intellectual and material resources, language and universe of questions'. Both takes on the theme can also be found in Ulnicane's account of nanotechnology collaborations and her reference to Crane's 'invisible colleges'. On the one hand, this account refers to more or less stable entities like disciplines or research organisations, on the other hand it emphasises collaboration on the basis of complementary expertise and heterogenous roles, as well as influences from an extra-scientific arena. Wylie refers to Fleck's 'thought collectives' and to Kuhn, but also evokes ethnographies like the one by Traweek (1988), and refers to Lave and Wenger's 'communities of practice'.

Lave and Wenger's 'communities of practice' (Lave and Wenger 1991; Wenger 1998) play a major role in Jarke's account of two half manufactured, half emerging European communities of eGovernment practitioners. She provides a very different case to, and scholarly references from, Degelsegger-Márquez, yet with just as much 
theoretical emphasis when establishing her concept of a 'community by template'. She delineates the career of Lave and Wenger's concept in various bodies of literature, from the initial ambition 'to investigate learning as a social and situated practice', to first attempts at nurturing such communities so as to enhance organisational productivity, and finally to contemporary initiatives to establish or build trans-local, virtual 'communities of practice'. Along this observed development in theoretical and practical contexts, the relation of distributed practice, exchange relations, objects of exchange, community, and membership plays a crucial but ambiguous role. These are obviously co-created in some way, while the strict uni-directional causalities along a one-dimensional ontology searched for by management scholars somehow evades the analyst's gaze. As an answer to the analytical aspect of this twofold problem, the author opts for a practice or processoriented approach, inspired by Cooper and Law's (1995) 'proximal view' and Mol's (2003) praxiography. She contrasts two cases of community formation that both build on an exchange of digital templates dedicated to the sharing of practical examples and expertise among such practitioners. In the first case, the template was prepared by the European Commission and fixed; in the second case, the template was developed by a network of distributed practitioners and open for further adoption. The two cases exhibit different kinds of interaction, circulating different kinds of objects and negotiating different dimensions of collectivity, and they result in different kinds of community. She outlines two 'different levels of sharing and different forms of communality' that emerge in the two settings and concludes that 'knowledge objects such as templates are not simply a means to actively share practices but rather a means for enacting membership'. We are left in limbo, not only by this chapter but also the many other attempts at 'community building' that we observe in the context of proclaimed emerging technosciences that stay ambiguous about their goals (nurturing existing or building new communities as an end in itself or with an overarching ambition) and lack follow up such as reports on later outcomes and related further steps. Continuing to trace through the 'emergence' with longer term analyses is work that remains to be done.

The above-mentioned theoretical ambiguities arise mostly in relation to an unclear character of the social phenomena being addressed. These range from project groups to laboratory teams or organisation; from sub-fields and specialties to disciplines; from collaborative networks to research schools; from proclaimed to manufactured emergences of community. All of these entities are analysed in reference to aspects of community. As, for instance, Cointe notes in her chapter: 'projects create communities - these are provisional, more or less loose, and may not outlast the project, but they are communities nonetheless, in that they are united by shared objectives and resources'. In reference to Leonelli and Ankeny (2015) she adds that 'projects also contribute to shaping and reconfiguring existing scientific communities'. The same may apply for the interdisciplinary research collaborations analysed by Ulnicane or for the research laboratory teams analysed by Wylie, whereas proclamation and manufacturing of community feature centrally in the accounts of Blümel and Jarke. 
The diversity of phenomena and the ambiguities inherent in these accounts do not help with clarifying the theoretical conception of scientific communities in any categorical sense. At most, they help with clarifying instances of when and how aspects of community (as opposed to aspects characteristic of networks, organisations, or society) become decisive. Going back to Mullins' four stage model it is probably the cluster phase in which this is most perceptible. It follows the stage of communication networks and is later superseded by the institutionalisation of a specialty. According to Mullins, a cluster is 'a collective entity recognised and constituted as such by its members' with 'a shared directory of resources' such as textbooks translated into different languages, new dedicated journals, and symposia. It thereby stretches beyond existing local groups but still possesses a very personal character in 'key meetings' and at 'melting pot sites'. These meetings and sites also serve as a playground for affective, charismatic, or dogmatic dynamics that result in accounts of a distinct habitus within a nascent field, spanning the professional as well as private persona of the protagonists, or the formation of strong social ties so lively depicted in Mullins' account and interview quotations. In a similar vein, Ulnicane depicts 'hot fields' and characterises them as having intense interaction, communication, and rivalry; interdisciplinarity; a strong focus on training; and research groups comprising complimentary expertise. With its charismatic or dogmatic dynamics, the cluster stage or its contemporary technoscientific equivalent of a 'hot field' serve well to establish a common culture as addressed in the comparative reconstructions of scientific fields (Bourdieu 1975), evidential cultures (Collins 1998), epistemic cultures (Knorr-Cetina 1999), or techno-epistemic cultures (Kastenhofer 2013). Both aspects are then combined in the notion of 'epistemic communities' put forward by Meyer and Molyneux-Hodgson (2010).

\subsubsection{The Social Engineering of Community}

A fourth aspect of addressing scientific community in singular and plural that has already been mentioned above is their link to an instrumental dimension, or, in other words, to a vision of socially engineering science and its outputs. This link is most explicitly drawn by Jarke when she refers to Lave and Wenger's 'communities of practice' and the twofold career of this concept in both analytical and interventionist approaches. While the ambiguous causal (and ontological) relationship of practice, interaction, and community within such communities can be addressed analytically by a practice-oriented approach that highlights processes of co-performance and co-production, the interventionist position is held in limbo. The questions of where to intervene, when to intervene, with which approach, and to what ends, hang in the air of technoscientific innovation regimes without clear answers. At the same time, descriptions of 'socially engineering emergence' and their emergent fields pile up. As Ulnicane quotes with regard to bottom-up, self-organised global networks of research, 'these networks cannot be managed; they can only be guided and influenced' (Wagner 2008, p. 105). Attempts at community making or community 
building can appear as interventions as an end in themselves when the potential to reach a specific goal with a specific intervention stays unclear.

\section{6 'Choreographing Identities': From Identity Trouble to Strategic Performance}

The chapters in Part I share a primary focus on matters of collectivity and the specificities of community in the sciences. They also, unavoidably, touch upon issues of identity: addressing individual researchers' roles and memberships and identities conferred by social collectives. They demonstrate that whatever the methodological approach-ethnographic or scientometric, with a focus on practices or discourses, on collaborations, networks, or fields-community and identity are intrinsically interwoven. Moreover, the terms 'community' and 'identity' both belong to a kind of vernacular category that research studies cannot totally ignore but that often stays at arm's length to a satisfying theoretical conceptualisation. As such, questions of community and identity have been re-addressed, reformulated, and conceptualised anew by almost every theoretical approach adopted in the analysis of scientific endeavour. This problematic is exacerbated for questions of identity in particular, questions that clearly transgress the disciplinary boundaries of sociology. Identity has been a classical theme for philosophers, psychologists, and cultural scientists, but it is only indirectly, for example with its unavoidable link to community or its inherent political dimension, that it comes within some sociologists' range of vision as a theme of reconstruction or deconstruction. As a result, identity has become a 'suspect category' on epistemic as well as political grounds, while remaining an inevitable theme on empirical grounds.

The chapters of Part II provide us with examples of how identity comes to matter in empirical cases and how it can be conceptualised and inform theoretical discourse. None of the authors would likely consider themselves as identity theorists; rather, they navigate phenomena relating to matters of identity in their empirically grounded work and consequently integrate these into case accounts and case analyses. It is all the more interesting, then, to look at the theoretical approaches to identity that the chapters engage and confront.

\subsubsection{Becoming and/or Performing?}

The need for scholarly attention to educational trajectories cannot be over stated. Wylie cogently attends to this concern with a focus on the interplay between the identities of 'novice' and 'expert' in a university engineering context. This work throws light on to new ways of thinking about learning as inherently part of identitymaking performance. 
Sarah Rachel Davies addresses in her chapter the challenging issue of conceptualising identity upfront when she contemplates that she is 'working with a generous definition of identity [...] as relating to role, boundary work (or role differentiation), and community.' Still, she does situate her work in a clearly denoted theoretical tradition, building on Goffman's performed self or 'performed character' and his distinction between 'front stage' and 'back stage' performance. She also draws on Hilgartner's (2000) analysis of 'Science on Stage' and his recognition that 'scientists are not 'con men', they simply have 'multiple identities' (ibid, p. 13). Along these lines, Davies' conception of performed identity is processual, contextual, multiple, and multivalent. It necessitates an actor, a character, a theatre, a stage, and an audience. The theatre and stages she focuses on in her participatory ethnography are provided by a science festival that took place over 6 days in Copenhagen in June 2014, zooming in on three particular science communication projects by means of a 'thick description'. Multiplicity, here, refers to performances of individual, group, disciplinary, and organisational identity. Simultaneous performance of, for example, a personal as well as a professional script is possible because both are underdetermined: 'The role of scientist is not highly scripted: one might play it [...] as an addendum to a leisure identity; or [...] as a social character, part of the production of enjoyable community (p. 220).'

But there is also a more reifying layer when Davies speaks of 'identity building' as additional to 'identity performance'. The building of identity as, for example, a university employee is something she experiences herself, back stage during her involvement in a science festival, whereas identity performance is something she observes on the front stages of the science communication theatre (and at several back stages that themselves function as front stages of yet again other kinds of performances). Identity thus is implicitly presented as double sided, just as is explicitly done in Caitlin Donahue Wylie's account (the latter referring to Stevens et al. 2008), but with two different qualities for the two different sides: built (over time as an inner sense of belonging) and performed (ad hoc by 'harried fabricators of impressions', to adopt Goffman's wording). One could argue that with the depiction of identity building processes, Davies highlights a moment 'in which identityformation becomes more settled and routinized', that maybe contributes to the furthering of 'the narrative infrastructures [Felt 2017] that make [situated identity performances] possible', while the material infrastructure of the festival

became lived in: things broke and were stuck back together, the marquee took on a distinctive smell, we became familiar with each other and with the tent's soundscape [...] The community of the tent, both human and non-human, became deeply familiar (p. 218).

That is, at least, if we assume that the script for 'residing in a tent for six days as a University of Copenhagen employee' is not totally fixed from the beginning.

That both dimensions and relating conceptions of identity-(inner) becoming and (staged) performance-reside closely to each other should not gloss over that a deep theoretical gap runs between the two. In the cautionary words of Lewis P. and Sandra K. Hinchman: 


\begin{abstract}
When we spin narratives that form our personal identity, are we creating order out of chaos, i.e. out of a manifold of disordered impressions, sensations, memories, and inner states? Or does the narrative self somehow correspond to, or perhaps develop and articulate, a pre-narrative identity that is already there 'in itself,' antecedent to the narrative that constructs it? This obviously Kantian dilemma splits narrativists down the middle (Hinchman and Hinchman 1997, p. xix).
\end{abstract}

A gap that Wetherell (2010, p. 10) attributes to 'priority disputes between sociology and psychology' (quoted by Cuevas in this volume). It is perhaps owing to Davies' method of participatory observation that both these aspects come to the fore. Her involvement as scientist and university employee, as a member of 'the community of the tent', renders the first aspect conspicuous, although at a second glance the aspect of becoming can also be traced in the accounts of the other two projects in which the author participated as audience only.

\title{
1.6.2 Choreographing and Repairing Breaches of Canonical Narratives as Specific Kinds of Identity Work
}

Andrea Schikowitz's chapter also addresses both becoming and performing, but within a theoretical approach, empirical context, and (longer) time horizon where both aspects merge in multivalent identity work or a practice of 'choreographing'. She builds on Swidler (1986) and Butler (1990) and starts with an historical account of how belonging to disciplinary scientific communities became more fluid and diverse over time to a point where - at least in some realms of science-belonging is characterised by permanent change and necessitates an 'identity beyond community' established by a distinct kind of reactive as much as proactive identity work, performed to 'to establish, adapt, and maintain positions'. In her empirical case, to an even higher degree than in Davies' empirical case, identities and relating scripts are not pre-given, i.e. already established in other contexts). She investigates eleven projects funded within a transdisciplinary sustainability research programme in Austria between 2004 and 2012. Drawing on interviews, focus groups, and ethnographic observation, she highlights the distinct kind of identity work that comes with an 'identity beyond community' and introduces the concept of 'choreographies'. Other than disciplinary identities, these choreographed identities can be taken along, like a suitcase, when travelling from one disciplinary realm to another or when residing in between communities. The account thus evokes a picture of disciplinary residents and transdisciplinary nomads. 'The notion of choreography includes performance, and it directs attention to how different belongings and ideals in different moments might be related through "dance instead of design" (Law 2003 , p. 58)' is to be understood 'as a subtle relation of rules, routines, situated responses, and improvisation'. Four distinct choreographies or choreographed identities emerge from her analysis: an 'explorer', a 'caring broker', a 'moral manager', and a 'polymath', all of which exhibit distinct move patterns, identity work, socialities, and collective orders (see below for the latter). 
Carlos Cuevas-Garcia is also concerned with the troubled identities of researchers, specifically those transgressing disciplinary boundaries throughout their careers. He analyses how 27 scientists at a 'large research-oriented British university' and from a variety of (inter)disciplinary fields depict their academic backgrounds in biographical interviews. Like Schikowitz he precedes his empirical analysis with a note on disciplinarity but focuses on the heterogeneous, hybrid, internally fragmented, constantly renegotiated, and to some extent illusionary character of disciplines, rendering them 'real [mostly] in their consequences'. Disciplinary identity is depicted as flexible, rhetoric, contextual, multiple, fluid, and tentative, interdisciplinarity as possibly a common practice rather than a deviant one. The author also invokes the schism between 'personal' and 'social' conceptions of identity — as addressed by Hinchman and Hinchman 1997 and Wetherell 2010, and labelled as becoming and performed above-pondering that all these characterisations might only apply to the latter conception. His own approach is an attempt at abandoning the dichotomy altogether, following the integrative perspective of a discursive psychology. He thus combines an analysis of biographical narratives with an analysis of metaphors capturing inter/disciplinarity. He particularly focuses on canonical narratives and on narratives of breach, trouble, and repair, as conceptualised in Taylor and Littleton's (2006) narrative-discursive analytical approach. With four exemplar interviews, he illustrates major differences, differences that can be explained by particular life trajectories of individual researchers but also by the particularities of the respective core disciplines of the interviewees. Albeit using variations, all interviewees relate to a 'canonical narrative of the single discipline specialist', including an early interest, passion, and skills in a specific discipline; early ambition and clear career goals; training and experience within the same discipline to $\mathrm{PhD}$ and beyond; and repair work when breaches occur. Repair, Cuevas-Garcia suggests, allows tensions to be eased, the gap between the fixed and the flexible and fluid to be closed, and an individual position to be developed.

Bettina Bock von Wülfingen's contribution provides a further case of troubled identities. Her analysis of identity work and identity fate at an interdisciplinary German Cluster of Excellence is based on a participatory ethnography and details the external and internal governance regimes determined by national science policy in the steering of the Cluster. She provides an overview of the scholarly discussion of scientific community and the social psychology of belonging. Based on her empirical material, she focuses on short term reactions to the unsettling of disciplinary identities as well as on types of collaborative identity that emerge within the Cluster's interdisciplinary constellation as it establishes its own research community over time. She thereby sketches individual differences that come to matter, such as the 'academic pedigree' or the career stage of the respective scientists, and structural conditions that co-determine the potential for interdisciplinary identity formation. She concludes that the formation of 'collaborative identities' is possible and builds on a more general academic self-conception, beyond academic biographic aspects. 


\subsubsection{The Affective Dimension}

Bock von Wülfingen and Cuevas-Garcia touch on the affective dimension of the unsettling of identity. In the biographical interview sections presented by CuevasGarcia, we learn how an affective layer is co-constitutive of the narrated self-even when disciplinary boundaries are not challenged. The emotions featured in the scientists' accounts span a somewhat proscribed spectrum however, from excitement, fascination, enjoyment, being captivated and interested, to surprise and experiences of not feeling stupid anymore, or being able to escape a 'dirty nasty job'. This peculiarity of an omnipresent but highly defined and somewhat meagre affective repertoire is further explored by Sarah Maria Schönbauer. She 'decided to explicitly focus on the scientists' emotional engagement with their profession since relating to their community by "associating emotional states with certain activities" (Traweek 1988, p. 76) turned out to be one of the core concerns' of the group leaders and senior postdocs in the biographical interviews she had undertaken as part of an ethnographic field study in 2013 in the United States and Austria. With the specific sample of interviewees, affective narratives covering their own early career stages were a way of stabilising their own meaningful identity, belonging to a respective community (by conforming to its 'emotional culture' and distinct 'feeling style', Parker and Hackett 2012) and relating to a next generation of scientists. After sketching literature that highlights the importance as well as ambivalence of passion and being passionate within science from Max Weber and Robert Merton to contemporary scholars, the author concentrates on the role passion plays in the scientists' accounts of their different career stages, especially when it comes to insecurities, inconsistencies, and discontinuities. She addresses the first phase of choosing a field and curriculum, which is characterised by 'fascination' (comparable to Cuevas-Garcia's account), an ensuing phase of 'committing to science' marked by spatial and temporal concessions, and a third phase of 'imagining a future generation of scientists'. She concludes that 'passionate tales provide some order in and for scientific communities and show that the scientists' emotional relationship with their profession is key to understanding the construction of their identities' (p. 296). Passionate tales 'provide the scientists with continuity by constructing an emotional track record', and passion also seems to provide a drive in the scientists' accounts that allows for overcoming situations of unease. Demonstrating passion thus could also be interpreted by actors in the field as a sign of being able and willing to cope with the adversities of contemporary lives in science and hence translate into a sort of affective capital, just as demonstrating mobility can be interpreted as a proof of commitment to the collective and hence as a value in itself.

A recurring, though not fully elaborated, role in Schönbauer's treatise is assigned to scientists' (assumed) need for security, stability, continuity, coherence, and connection. This resonates with Cuevas-Garcia's reference to some scholars' assumption that 'interdisciplinary researchers have a sense of vulnerability, tension and insecurity'. One might ask whether this_-perhaps psychological a priori_could 
be challenged or rephrased in relation to contemporary scholars' acknowledgment of the distinctive role of the unstable, fluid, and fuzzy in the sociology of the sciences.

Davies' account of a science festival adds further hints to the role emotions play in staging science in public. One scientist aims for establishing a specific kind of emotional connection between the lay audience and the beluga whales featured in his exhibition as 'looking straight at you'. Another aims at depicting a science that 'first makes people laugh, and then makes them think' and then 'appreciate the wonders of scientific thinking' to 'understand how fun and interesting and beautiful science is'. Emotions evoked by pictures or performance are thus depicted as a 'natural bridge' between academia and lay audience. In the first case, evoking a certain emotional state of feeling connected to the 'natural world' (and hence caring for it) is often claimed as a central ambition of the science communication project.

\subsection{A Preliminary Conclusion}

The papers considered here demonstrate that concern and debates regarding collectivity and identity in contemporary sciences are very much alive. Authors tackle a range of contemporary phenomena that intersect with these two main concepts, including: digitalisation; mediatisation; projectification; phenomena of up-sizing (massification and Big Science); hybridisation, post-disciplinarity or 'new disciplinarity' (Marcovich and Shinn 2011); mission orientation; new funding environments; and more. The chapters of the volume thereby renew our attention to both longstanding and novel conceptual matters and, in effect, survey the impact of these shifts in the 'machineries of knowledge production' (Knorr-Cetina 1999), with a view to demonstrating (techno)scientific identity constellations and (techno)scientific communality as integral parts of such machineries.

It may be more than a mere coincidence that the empirical examples of this volume stem for the most part from synthetic biology, bioinformatics and sustainability sciences. All of these realms of research seem to have more in common than one would assume at first glance (given their quite different disciplinary backgrounds and, arguably, conflicting societal visions). Not only are the field formations highly interdisciplinary, the fields can also be viewed as 'umbrella terms' (just like nanotechnology, cp. Rip and Voß 2013), 'strategic science' (Rip 2002) and as 'new and emerging' (or maybe better: 'ephemeral') science. It would be interesting to reconstruct the technoscientific features they share more broadly in more detail. The analysis of identity and community constellations in these fields could serve as a valuable way in for such an endeavour. We thus hope that this volume can also contribute to a further delineation of technoscience and its distinct qualities.

Technoscientific communities are addressed as emergent and heterogenous, but also as rhetorically fabricated and socially engineered phenomena. Some authors align their analyses of emergence with classical studies that tell us a story about several phases leading to the final maturation and institutionalisation of a field, but hint at a distinct quality of this mature state of contemporary fields (Noël, Blümel); 
others underline that contemporary fields are characterised by a kind of "perpetuated emergence' (Raimbault and Joly). Further terms put forward to signify a qualitative singularity of community in contemporary technosciences are 'project-ed community' (Cointe, addressed also by Ulnicane and Jarke) and 'community of knowledge application' (Degelsegger-Márquez, addressed to some extent also by Jarke). Thetraditionally ignored and probably enhanced-agency of early career scientists (Wylie), of 'communities of practice' (Wenger 1998) as sites of (engineered) communality (Jarke) is pointed to in two further texts. Ulnicane allows for discussing 'internal' versus 'external' steering and its effects on scientific community (or, more specifically, collaboration) and Bock von Wülfingen adds an analysis of the effects interdisciplinary clusters of excellence have on community and identity in science.

Contemporary technoscientific identities are characterised as 'choreographed' (Schikowitz), 'troubled' (Cuevas-Garcia, but also Bock von Wülfingen), and 'staged' (Davies) - at first sight leaving meagre or only superficial options for a science worker to identify themselves as 'scientist' or with a distinct scientific field. But on closer look, adopting a choreographed identity seems to just become part of a scientists self-concept, the 'troubled' identity is 'repaired', the process of 'only staging' an identity in public leaves traces on a deeper level of self-identification, leading to for instance to a stronger identification with one's academic institution (Davies). A lack of options for (disciplinary) identification is answered by filling in alternative sources of identity like one's 'academic pedigree' in the short run or an interdisciplinary identity in the longer run (Bock von Wülfingen), a kind of repair work that goes along with a process of regrouping along traits alternative to or at least adding to disciplinary affiliations (also illustrated by Schikowitz and CuevasGarcia).

Whereas emotions and affect appear repeatedly in various chapters (even if only with a highly confined spectre, in a highly disciplined manner, and mostly in connection with participatory observation), a further discourse within the contemporary sociology of science literature, namely that on care and caring, is mostly absent from the accounts. Schikowitz delineates the figure of the 'caring broker'; Davies' reports on the caring marine biologist and the maintenance work undertaken by the 'community of the tent'; Raimbault and Joly's entrepreneurial scientists engage in the construction of a scientific community while PI's teach, supervise, and mentor novices. The list of empirical instances that would invite a focus on the role of care and caring is long. Still, this dimension remains largely unaddressed. Also, in most chapters it is unclear how the authors came to care about the fields they decided to investigate, in many cases to even participate in. We might deduce that addressing and exhibiting care is just as much a taboo in the sociology of the sciences as it is in the natural science fields studied in this volume. With new discourses emerging on care and responsibility within science studies and beyond, we wonder whether individual actors and communality might again gain more attention.

While many contributions in this volume focus on processes of field emergence rather than 'mature fields' and thereby contribute detailed analyses of a theme less 
often featured in the sociology of sciences, they do not include clues about the opposite process, the demise, ceasing to be of research fields. Such processes could be interesting especially against a context of fields or communities that seem to be stabilised by external forces, by science funding programmes and other attempts at manufacturing scientific communities. What exactly happens when these forces subside? The same could be asked about identities: when and how does a scientist disengage with a specific identifier and its relating community, when and why does one refuse to take on a specific identity? ${ }^{8}$ Are there contexts in science where community membership and identification with one's profession are never an option? How often can one adopt and abandon an identity and community and which traces does such a process leave in a scientific career and community?

Although not one contribution focusses on the more general level of the identity of researchers as scientists, many chapters include analyses that relate to this level when discussing the more specific identities of lab members, project participants or new disciplinarians. It is mostly in the literature on new public management at universities that shifts in identity options and relating tensions between academic and managerial identities are reported and discussed (Henkel 2000; Winter 2009). They are obviously linked to the general trends already enlisted above. Is it then still possible to identify with a traditional academic identity and role? Or have we already ceased to be academics and morphed into research managers a long time (i.e., some major projects and collaborations) ago? Are we part of a republic of (coequal) scholars and the vocation that comes with it, of a scientific community with its distinct ethos and societal status or of a global innovation machinery, based on role differentiation, division of labour and clear output definitions? How do quality/ qualification, ethos and responsibility fare in these contexts? Which stories are told and sold to the public about these (new) identities? And where do we want go from there?

Although the volume is divided into two sections, the entanglements between collectivity and identity are clearly visible, albeit not trivial or tangible in all respects. Much about their interrelation stays implicit and taken for granted. Being a member of a group, a community or an institution, sharing an educational background and socialisation, all provide senses of belonging, go with certain kinds of identification and add to a list of potential identifiers. Identity thus seems to relate individuality and communality in a plurality of ways. Both, (techno)scientific identity and community also come with an emotional as well as an instrumental dimension, with an aspiration to make sense (who am I? where do I belong to?) as well as strategic desires (how can community be engineered in a way that maximises productivity? How can identity be choreographed so as to provide the best career options?).

\footnotetext{
${ }^{8}$ In July 2019, a workshop organised by Kastenhofer and Vermeulen at the International Society for the History Philosophy and Social Studies of Biology (ISHPSSB) biennial meeting in Oslo addressed such a theme from multiple disciplinary and transdisciplinary angles under the heading 'Should we stay or should we go now?' with a focus on why, when and how scholars stop working on or in an 'emerging field' such as systems biology; a relating paper is in preparation.
} 
The assumption of a co-productive relation between (techno)scientific and social orders, most clearly delineated in Jasanoff (2006), has been addressed at the beginning of this chapter; it is also touched upon in many chapters of this volume. In particular, the impact of science policies and science funding programmes (addressed more broadly in Whitley et al. 2010) and programmatics on (techno)scientific identity and communality are invoked in various of the case studies. There is, however, less emphasis here on how technoscience co-produces social order beyond the realms of academic research and education. New modes of biosociality, for example, those co-produced by genetic testing and the emerging category of genetic kinship, or, the emerging, datafied understanding of identity related to the discourse on 'identity theft', are just two cases of such co-productions triggered by technoscientific practices and requiring further attention beyond the confines of this volume. ${ }^{9}$

In extra-scientific contexts, an essentialist take on identity and community has of late been severely drawn into question once again with the phenomenon of so-called identitarian movements, necessitating us to re-think what exact status the aforementioned aspirations and desires should be attributed with and how this allows for their instrumentalisation along vested interests and particular kinds of political ideologies. Does it suffice here to allude to the very different context of science as compared to society at large, to a categorical difference between scientific community and scientific identity as compared to community and identity in society? If so, we would once more need a better understanding of how the concepts of community and identity change when transferred from general sociology to a sociology of science. If not, it will not suffice to just ignore the roles identity and community play and how these are played with in our machineries of knowledge production.

On a final note, this volume is also about the community/communities and identity/identities of a contemporary sociology of science. Addressing longstanding concerns of community and identity also involves a good portion of communitarian activity and identity work in itself. One might assume that such activity and work will need both, space and tolerance for innovation and diversification, but also distinct opportunities and places for stock taking and joint discussions. For both we see this Yearbook series as a valuable resource and hope it will further prosper during the years to come!

\footnotetext{
${ }^{9} \mathrm{We}$ thank one anonymous reviewer and the participants of a course on 'identity and community and how they come to matter in contemporary technoscience' held at the department of science and technology studies at the University of Vienna in 2019 for drawing our attention to this specific limitation of the volume.
} 


\section{References}

Abir-Am, P. 1985. Themes, genres and orders of legitimation in the consolidation of new scientific disciplines: Deconstructing the historiography of molecular biology. History of Science 23 (1): 73-117.

Arnold, M., and R. Fischer, eds. 2004. Disziplinierungen. Kulturen der Wissenschaft im Vergleich. Wien: Turia + Kant.

Balmer, A.S., and K.J. Bulpin. 2013. Left to their own devices: Post-ELSI, ethical equipment and the International Genetically Engineered Machine (iGEM) competition. BioSocieties 8 (3): 311-335.

Balmer, A.S., K. Bulpin, and S. Molyneux-Hodgson. 2016. Synthetic biology: A sociology of changing practices. Basingstoke: Palgrave Macmillan.

Bastide, F., J.P. Courtial, and M. Callon. 1989. The use of review articles in the analysis of research data. Scientometrics 15: 535-562.

Bauman, Z. 2004. Identity. Conversations with Benedetto Vecchi. Cambridge: Polity Press.

Beaufaÿs, S. 2003. Wie werden Wissenschaftler gemacht? In Beobachtungen zur wechselseitigen Konstitution von Geschlecht und Wissenschaft. Bielefeld: Transcript Verlag.

Becher, T., and P.R. Trowler. 2001. Academic tribes and territories. Intellectual enquiry and the culture of disciplines. 2nd ed. Buckingham: SRHE and Open University Press.

Becker, H.S., B. Geer, E.C. Hughes, and A.L. Strauss. 1961. Boys in white: Student culture in medical school. Chicago: University of Chicago Press.

Ben-David, J., and R. Collins. 1966. Social factors in the origins of a new science: The case of psychology. American Sociological Review 31 (4): 451-465.

Böhme, G., W. van den Daele, and W. Krohn. 1973. Die Finalisierung der Wissenschaft. Zeitschrift für Soziologie 2 (2): 128-144.

Bonneuil, C. 2006. Cultures épistémiques et engagement public des chercheurs dans la controverse OGM. Natures Sciences Sociétés 14: 257-268.

Böschen, S., K. Kastenhofer, I. Rust, J. Soentgen, and P. Wehling. 2010. Scientific nonknowledge and its political dynamics: The cases of agri-biotechnology and mobile phoning. Science, Technology, and Human Values 35 (6): 783-811.

Bourdieu, P. 1975. The specificity of the scientific field and the social conditions of the progress of reason. Social Science Information 14 (6): 19-47.

Brown, N. 2003. Hope against hype: Accountability in biopasts, presents and futures. Science Studies 16 (2): 3-21.

Bulpin, K., and S. Molyneux-Hodgson. 2013. The disciplining of scientific communities. Interdisciplinary Science Reviews 38 (2): 91-105.

Butler, J. 1990. Gender troubles: Feminism and the subversion of identity. New York: Routledge.

Calvert, J. 2010. Systems biology, interdisciplinarity and disciplinary identity. In Collaboration in the new life sciences, ed. J.N. Parker, N. Vermeulen, and B. Penders, 201-218. Aldershot: Ashgate.

Chari, D.N., R. Howard, and B. Bowe. 2012. Disciplinary identity of nanoscience and nanotechnology research - A study of postgraduate researchers' experiences. International Journal for Digital Society 3 (1): 619-616.

Cointe, Béatrice. this volume. The project-ed community. In Community and identity in contemporary technosciences, Sociology of the sciences yearbook 31, ed. K. Kastenhofer and S. Molyneux-Hodgson. Cham: Springer.

Collins, H.M. 1981. The place of the 'core-set' in modern science: Social contingency with methodological propriety in science. History of Science 19 (1): 6-19.

- 1998. The meaning of data: Open and closed evidential cultures in the search for gravitational waves. American Journal of Sociology 104 (2): 293-337.

Cooper, R., and J. Law. 1995. Organization: Distal and proximal views. Research in the Sociology of Organizations 13: 237-274. 
Crane, D. 1972. Invisible colleges: Diffusion of knowledge in scientific communities. Chicago: University of Chicago Press.

Damm, U., B. Hopfengaertner, D. Niopek, and P. Bayer. 2013. Are artists and engineers inventing the culture of tomorrow? Futures 48: 55-64.

Daston, L. 2003. Die wissenschaftliche Persona. Arbeit und Berufung. In Zwischen Vorderbühne und Hinterbühne. Beiträge zum Wandel der Geschlechterbeziehungen in der Wissenschaft vom 17. Jahrhundert bis zur Gegenwart, ed. T. Wobbe, 109-136. Transcript: Bielefeld.

Daston, L., and P. Peter Galison. 2007. Objectivity. New York: Zone Books.

Daston, L., and H. Sibum. 2003. Introduction: Scientific personae and their histories. Science in Context 16 (1-2): 1-8.

De Solla Price, Derek J. 1963/1971. Little science, big science. New York/London: Columbia University Press.

Dixon, J., and N. Kuldell. 2011.Biobuilding: Using banana-scented bacteria to teach synthetic biology. In Methods in enzymology, Vol 497: Synthetic biology, Methods for part/device characterization and chassis engineering, Pt A, ed. C. Voigt, pp. 255-271.

Elzinga, A. 1993. Science as the continuation of politics by other means. In Controversial science. From content to contention, ed. T. Brante, S. Fuller, and W. Lynch, 127-152. Albany: State University of New York Press.

Felt, U., ed. 2009. Knowing and living in academic research: Convergences and heterogeneity in research cultures in the European context. Prague: Institute of Sociology of the Academy of Sciences of the Czech Republic.

- 2016. Of timescapes and knowledge spaces: Re-timing research and higher education. In New languages and landscapes of higher education, ed. P. Scott, J. Gallacher, and G. Parry, 129-148. Oxford: Oxford University Press.

- 2017. 'Response-able practices' or 'new bureaucracies of virtue': The challenges of making RRI work in academic environments. In Responsible innovation 3: A European Agenda? ed. L. Asveld, M. van Dam-Mieras, T. Swierstra, et al., 49-68. Cham: Springer.

Felt, U., J. Igelsböck, A. Schikowitz, and T. Völker. 2013. Growing into what? The (un-)disciplined socialisation of early stage researchers in transdisciplinary research. Higher Education 65: 511-524.

Fleck, L. (1983 [1947]). Schauen, sehen, wissen (T. Schnelle, Trans.). In Ludwik Fleck. Erfahrung und Tatsache. Gesammelte Aufsätze, ed. L. Schäfer and T. Schnelle, 147-174. Frankfurt/Main: Suhrkamp.

Fligstein, N., and D. McAdam. 2012. A theory of fields. Oxford/New York/Auckland: Oxford University Press.

Frickel, S. 2004. Building an interdiscipline: Collective action framing and the rise of genetic toxicology. Social Problems 51 (2): 269-287.

Frickel, S., and N. Gross. 2005. A general theory of scientific/intellectual movements. American Sociological Review 70 (2): 204-232.

Frickel, S., and K. Moore, eds. 2005. The new political sociology of science: Institutions, networks, and power. Madison: University of Wisconsin Press.

Frow, E., and J. Calvert. 2013. 'Can simple biological systems be built from standardized interchangeable parts?' Negotiating biology and engineering in a synthetic biology competition. Engineering Studies 5 (1): 42-58.

Funtowicz, S.O., and J.R. Ravetz. 1992. Three types of risk assessment and the emergence of postnormal science. In Social theories of risk, ed. S. Krimsky and D. Golding, 251-273. Westport, CT: Greenwood.

Gibbons, M., C. Limoges, H. Nowotny, S. Schwartzman, P. Scott, and M. Trow. 1994. The new production of knowledge: The dynamics of science and research in contemporary societies. London: Sage.

Gieryn, T.F. 1983. Boundary-work and the demarcation of science from non-science: Strains and interests in professional ideologies of scientists. American Sociological Review 48 (6): 781-795. 
Gläser, J. 2006. Wissenschaftliche Produktionsgemeinschaften. In Die soziale Ordnung der Forschung. Frankfurt/New York: Campus.

Gläser, J., G. Laudel, and E. Lettkemann. 2016. Hidden in plain sight: The impact of generic governance on the emergence of research fields. In The local configuration of new research fields. On regional and national diversity, Sociology of the sciences yearbook 29, ed. M. Merz and P. Sormani, 25-43. Dordrecht: Springer.

Goodman, C. 2008. Engineering ingenuity at iGEM. Nature Chemical Biology 4 (1): 13-13.

Haas, P.M. 1992. Introduction: Epistemic communities and international policy coordination. International Organization 46 (1): 1-35.

- 1994. Do regimes matter? Epistemic communities and Mediterranean pollution control. In Comparative science and technology policy, ed. S. Jasanoff, 537-563. Cheltenham: Edward Elgar Publishing.

Hackett, E.J., and J.N. Parker. 2016. Ecology reconfigured: Organizational innovation, group dynamics and scientific change. In The local configuration of new research fields. On regional and national diversity, Sociology of the sciences yearbook 29, ed. M. Merz and P. Sormani, 153-171. Dordrecht: Springer.

Hacking, I. 2002. Historical ontology. Cambridge/London: Harvard University Press.

Hagstrom, W. 1965. The scientific community. New York: Basic Books.

Haraway, D. 1996. Modest_Witness@Second_Millennium.FemaleMan $\left(C_{-}\right.$Meets_Oncomouse ${ }^{\mathrm{TM}}$. New York: Routledge.

Harwood, J. 1993. Styles of scientific thought. The German genetics community, 1900-1933. Chicago: University of Chicago Press.

Henkel, M. 2000. Academic identities and policy change in higher education. London: Jessica Kingsley Publishers.

Hess, D.J. 2005. Antiangiogenesis research and the dynamics of scientific fields: Historical and institutional perspectives in the sociology of science. In The new political sociology of science: Institutions, networks, and power, ed. S. Frickel and K. Moore, 122-148. Madison: University of Wisconsin Press.

Hilgartner, S. 2000. Science on stage: Expert advice as public drama. Stanford, CA: Stanford University Press.

Hinchman, L.P., and S.K. Hinchman. 1997. Introduction. In Memory, identity, community: The idea of narrative in the human sciences, ed. L.P. Hinchman and S.K. Hinchman, xiii-xxxii. Albany: State University of New York Press.

Ibarra, H. 1999. Provisional selves: Experimenting with image and identity in professional adaptation. Administrative Science Quarterly 44: 764-791.

Jamison, A. 1997. National styles of science and technology: A comparative model. In Comparative science and technology policy, ed. S. Jasanoff, 69-83. Cheltenham: Edward Elgar Publishing.

Jasanoff, S., ed. 2006. States of knowledge: The co-production of science and social order. London/New York: Routledge.

Jenkins, R. 2014. Social identity. 4th ed. London/New York: Routledge.

Kastenhofer, K. 2013. Two sides of the same coin? The (techno)epistemic cultures of systems and synthetic biology. Studies in History and Philosophy of Biological and Biomedical Sciences 44 (2): $130-140$.

2016. 'I am a biochemist by training': identity and community in systems biology. Vienna STS Talk, 4 May 2016, University of Vienna, Austria. https://sts.univie.ac.at/einzelansichtnews-und-events/news/vienna-sts-talk-karen-kastenhofer/?no_cache $=1$. Accessed 14 August 2019.

Kelwick, R., L. Bowater, K.H. Yeoman, and R.P. Bowater. 2015. Promoting microbiology education through the iGEM synthetic biology competition. FEMS Microbiology Letters 362 (16).

Knorr-Cetina, K. 1982. Scientific communities or transepistemic arenas of research? A critique of quasi-economic models of science. Social Studies of Science 12 (1): 101-130. 
1999. Epistemic cultures: How the sciences make knowledge, 1-25. London/Cambridge: Havard University Press.

Kurath, M. 2010. Negotiating nano: From assessing risks to disciplinary transformations. In Governing future technologies. Nanotechnology and the rise of an assessment regime, Sociology of the sciences yearbook 27, ed. M. Kaiser, M. Kurath, S. Maasen, and C. Rehmann-Sutter, 21-36. Dordrecht: Springer.

Kurath, M., and S. Maasen. 2006. Toxicology as a nanoscience? - Disciplinary identities reconsidered. Particle and Fibre Toxicology 3: 6.

Kusch, M. 2010. Hacking's historical epistemology: A critique of styles of reasoning. Studies in History and Philosophy of Science 41: 158-173.

Lave, J., and E. Wenger. 1991. Situated learning: Legitimate peripheral participation. Cambridge: Cambridge University Press.

Law, J. 2003. Traduction/trahision: Notes on ANT. Lancester: Lancester University Press.

Lemaine, G., ed. 1976. Perspectives on the emergence of scientific disciplines. Chicago: Aldine.

Leonelli, S., and R.A. Ankeny. 2015. Repertoires: How to transform a project into a research community. Bioscience 65 (7): 701-708.

Lewis, J., and A. Bartlett. 2013. Inscribing a discipline: Tensions in the field of bioinformatics. New Genetics and Society 32 (3): 243-263.

Liebau, E., and L. Huber. 1985. Die Kulturen der Fächer. Neue Sammlung 3 (1985): 314-339.

Lorenz-Meyer, D. 2010. Possibilities of enacting and researching epistemic communities. Sociological Research Online 15 (2): 1-13.

Marcovich, A., and T. Shinn. 2011. Where is disciplinarity going? Meeting on the borderland. Social Science Information 50 (3-4): 582-606.

Mercer, D. 2015. 'iDentity' and governance in synthetic biology: Norms and counter norms in the 'international genetically engineered machine' (iGEM) competition. Macquarie Law Journal 15: 83-103.

Merton, R. K. (1993/1942). The sociology of science: Theoretical and empirical investigations. Chicago: University of Chicago Press.

Merz, M., and P. Sormani, eds. 2016a. The local configuration of new research fields. On regional and national diversity, Sociology of the sciences yearbook 29. Dordrecht: Springer.

- 2016b. Configuring new research fields: How policy, place, and organization are made to matter. In The local configuration of new research fields. On regional and national diversity, Sociology of the sciences yearbook 29, ed. M. Merz and P. Sormani, 1-22. Dordrecht: Springer.

Meyer, M., and S. Molyneux-Hodgson. 2010. Introduction: The dynamics of epistemic communities. Sociological Research Online 15 (2): 14.

Mol, A. 2003. The body multiple: Ontology in medical practice. Durham, NC: Duke University Press.

Molyneux-Hodgson, S., and M. Meyer. 2009. Tales of emergence-Synthetic biology as a scientific community in the making. BioSocieties 4: 129-145.

Mullins, N.C. 1972. The development of a scientific speciality: The phage group and the origins of molecular biology. Minerva 10 (1): 51-82.

Nordmann, A., H. Radder, and G. Schiemann, eds. 2011. Science transformed?: Debating claims of an epochal break. Pittsburgh, PA: University of Pittsburgh Press.

O'Malley, M.A., A. Powell, J.F. Davies, and J. Calvert. 2008. Knowledge-making distinctions in synthetic biology. BioEssays 30 (1): 57-65.

Osbeck, L.M., and N.J. Nersessian. 2017. Epistemic identities in interdisciplinary science. Perspectives on Science 25 (2): 226-260.

Parker, J.N., and E.J. Hackett. 2012. Hot spots and hot moments in scientific collaborations and social movements. American Sociological Review 77 (1): 21-44.

Paul, H. 2016. Sources of the self: Scholarly personae as repertoires of scholarly selfhood. Low Countries Historical Review 131 (4): 135-154.

Pickstone, J.V. 2001. Ways of knowing. A new history of science, technology and medicine. Chicago: University of Chicago Press. 
Raimbault, B., J.P. Cointet, and P.-B. Joly. 2016. Mapping the emergence of synthetic biology. PLoS One 11 (9): e0161522.

Rip, A. 2002. Regional innovation systems and the advent of strategic science. Journal of Technology Transfer 27 (1): 123-131.

. 2004. Strategic research, post-modern universities and research training. Higher Education Policy 17: 153-166.

Rip, A., and J.-P. Voss. 2013. Umbrella terms as mediators in the governance of emerging science and technology. Science, Technology \& Innovation Studies 9 (2): 39-59.

Serrano, L. 2007. Synthetic biology: Promises and challenges. Molecular Systems Biology 3: 158.

Shapin, S. 2008. The scientific life: A moral history of a late modern vocation. Chicago, IL: Chicago University Press.

Smolke, C.D. 2009. Building outside of the box: iGEM and the BioBricks Foundation. Nature Biotechnology 27 (12): 1099-1102.

Stent, G.S. 1968. That was the molecular biology that was. Science 160: 390-395.

Stevens, R., K. O’Connor, L. Garrison, A. Jocuns, and D.M. Amos. 2008. Becoming an engineer: Toward a three-dimensional view of engineering learning. Journal of Engineering Education 97 (3): 355-368.

Swidler, A. 1986. Culture in action: Symbols and strategies. American Sociological Review 51 (2): 273-286.

Taylor, S., and K. Littleton. 2006. Biographies in talk: A narrative-discursive research approach. Qualitative Sociology Review 2 (1): 22-38.

Traweek, S. 1988. Beamtimes and lifetimes. The world of high energy physicists. Cambridge/London: Harvard University Press.

Tsui, J., and A.S. Meyer. 2016. Modular projects and 'mean questions': Best practices for advising an international genetically engineered machines team. FEMS Microbiology Letters 363 (14).

Vermeulen, N. 2018. The choreography of a new research field: Aggregation, circulation and oscillation. Environment and Planning A 50 (8): 1764-1784.

Wagner, C.S. 2008. The new invisible college. Science for development. Washington, DC: Brookings Institution Press.

Weber, J. 2010. Interdisziplinierung? Zur Übersetzungspolitik einer neuen Technowissenschaftskultur. In Interdisziplinierung? Über den Wissenstransfer zwischen den Geistes-, Sozial- und Technowissenschaften, ed. J. Weber, 83-112. Bielefeld: Transcript.

Weingart, P. 2003. Growth, differentiation, expansion and change of identity - The future of science. In Social studies of science and technology: Looking back, ahead. Sociology of the sciences yearbook 23, ed. B. Joerges and H. Nowotny, 183-200. Dordrecht: Kluwer.

- 2012. The lure of the mass media and its repercussions on science. Theoretical considerations on the medialization of science. In The sciences' media connection - Public communication and its repercussions, Sociology of the sciences yearbook 28, ed. S. Rödder, M. Franzen, and P. Weingart, 17-32. Dordrecht: Springer.

Wenger, E. 1998. Communities of practice. Learning, meaning, and identity. Cambridge: Cambridge University Press.

Wetherell, M. 2010. The field of identity studies (introduction). In The Sage handbook of identities, ed. M. Wetherell and C.T. Mohanty, 3-26. Los Angeles/London/New Delhi: Sage.

Whitley, R. 1984. The intellectual and social organization of the sciences. Oxford: Clarendon Press.

Whitley, R., J. Gläser, and L. Engwall, eds. 2010. Reconfiguring knowledge production: Changing authority relationships in the sciences and their consequences for intellectual innovation. Oxford: Oxford University Press.

Winter, R. 2009. Academic manager or managed academic? Academic identity schisms in higher education. Journal of Higher Education Policy and Management 31 (2): 121-131. 
Open Access This chapter is licensed under the terms of the Creative Commons Attribution 4.0 International License (http://creativecommons.org/licenses/by/4.0/), which permits use, sharing, adaptation, distribution and reproduction in any medium or format, as long as you give appropriate credit to the original author(s) and the source, provide a link to the Creative Commons license and indicate if changes were made.

The images or other third party material in this chapter are included in the chapter's Creative Commons license, unless indicated otherwise in a credit line to the material. If material is not included in the chapter's Creative Commons license and your intended use is not permitted by statutory regulation or exceeds the permitted use, you will need to obtain permission directly from the copyright holder. 